\title{
Design, Fabrication, and Certification of Advanced Modular PV Power Systems
}

\section{Final Technical Progress Report}

T. Lambarski and G. Minyard

Solar Electric Specialties Co.

Willits, California

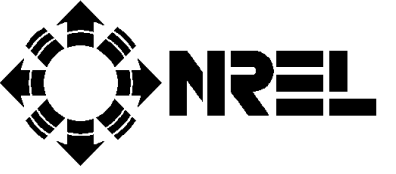

National Renewable Energy Laboratory 1617 Cole Boulevard

Golden, Colorado 80401-3393

A national laboratory of the U.S. Department of Energy Managed by Midwest Research Institute for the U.S. Department of Energy

under contract No. DE-AC36-83CH10093 


\section{Design, Fabrication, and Certification of Advanced Modular PV Power Systems}

\section{Final Technical Progress Report}

T. Lambarski and G. Minyard

Solar Electric Specialties Co.

Willits, California

NREL technical monitor: H. Thomas

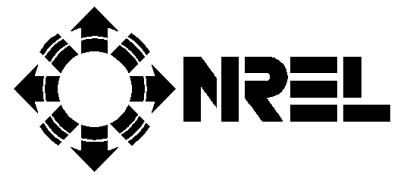

National Renewable Energy Laboratory 1617 Cole Boulevard

Golden, Colorado 80401-3393

A national laboratory of the U.S. Department of Energy Managed by Midwest Research Institute for the U.S. Department of Energy under contract No. DE-AC36-83CH10093

Prepared under Subcontract No. ZAF-5-14271-07

October 1998 
This publication was reproduced from the best available copy Submitted by the subcontractor and received no editorial review at NREL

\section{NOTICE}

This report was prepared as an account of work sponsored by an agency of the United States government. Neither the United States government nor any agency thereof, nor any of their employees, makes any warranty, express or implied, or assumes any legal liability or responsibility for the accuracy, completeness, or usefulness of any information, apparatus, product, or process disclosed, or represents that its use would not infringe privately owned rights. Reference herein to any specific commercial product, process, or service by trade name, trademark, manufacturer, or otherwise does not necessarily constitute or imply its endorsement, recommendation, or favoring by the United States government or any agency thereof. The views and opinions of authors expressed herein do not necessarily state or reflect those of the United States government or any agency thereof.

Available to DOE and DOE contractors from:

Office of Scientific and Technical Information (OSTI)

P.O. Box 62

Oak Ridge, TN 37831

Prices available by calling (423) 576-8401

Available to the public from:

National Technical Information Service (NTIS)

U.S. Department of Commerce

5285 Port Royal Road

Springfield, VA 22161

(703) $605-6000$ or (800) 553-6847

or

DOE Information Bridge

http://www.doe.gov/bridge/home.html 


\section{FINAL TECHNICAL PROGRESS REPORT}

\section{TABLE OF CONTENTS}

\section{EXECUTIVE SUMMARY}

1.0 INTRODUCTION 3

1.1 Background and Goals 3

1.2 Organization of Report 3

1.3 Task Descriptions 3

2.0 SUMMARY OF ACTIVITIES AND ACCOMPLISHMENTS 5

2.1 Task 1, Modular Autonomous Photovoltaic Power Supply (MAPPS)

2.2 Task 2, Modular Autonomous Photovoltaic Power Supply (MAPPS) $\begin{array}{ll}\text { Fabrication } & 6\end{array}$

2.3 Task 3, Design of $1 \mathrm{~kW}$ Photogenset 6

2.4 Task 4, Safety Certification 7

2.5 Task 5, Fabrication of $1 \mathrm{~kW}$ Photogenset 7

2.6 Task 6, Safety Certification 8

2.7 Task 7, Functionality Testing 8

2.8 Overall Accomplishments and Benefits of the Project 9

3.0 TASK EFFORTS AND ACTIVITIES 11

3.1 Administrative Activities 11

3.2 Task 1, Modular Autonomous Photovoltaic Power Supply (MAPPS)
Design

3.2.1 User Survey

3.2.2 MAPPS Design

3.3 Task 2, Modular Autonomous Photovoltaic Power Supply (MAPPS) Fabrication

\subsubsection{MAPPS Fabrication}

3.3.2 Process Specifications

3.3.3 Installation Manual

3.3.4 Future Product Line Standardization

3.4 Task 3, Design of $1 \mathrm{~kW}$ Photogenset 14

$\begin{array}{lll}3.5 & \text { Task 4, Safety Certification } & 15\end{array}$

3.5.1 Determination of Listing Requirements

3.5.2 Listing of MAPPS

3.5.3 Listing of Photogenset

3.6 Task 5, Photogenset Fabrication 18 


\section{TABLE OF CONTENTS (cont.)}

3.7 Task 6, Safety Certification

3.7.1 MAPPS Safety Certification

3.7.2 Photogenset Safety Investigation

3.8 Task 7, Functionality Testing

3.8.1 MAPPS Functionality Testing

3.8.2 Photogenset Functionality Testing

LIST OF FIGURES (at end of report)

MAPPS Block Diagram

Photograph of MAPPS at Installed NREL

Mobile Photogenset Block Diagram

Mobile Photogenset Trailer Plan View

Photograph of Array and Front of Mobile Photogenset

Photograph of Rear and North Side of Mobile Photogenset

Photograph of Mobile Photogenset Interior 


\section{EXECUTIVE SUMMARY}

Solar Electric Specialties Company (SES) has completed a two and a half year effort under the auspices of the U. S. Department of Energy (DOE) PVMaT (Photovoltaic Manufacturing Technology) project. Under Phase 4A1 of the project for Product Driven System and Component Technology, the SES contract "Design, Fabrication and Certification of Advanced Modular PV Power Systems" had the goal to reduce installed system life cycle costs through development of certified (Underwriters Laboratories or other listing) and standardized prototype products for two of our product lines, MAPPS ${ }^{\mathrm{TM}}$ (Modular Autonomous PV Power Supply) and Photogensets ${ }^{\mathrm{TM}}$. MAPPS are small DC systems consisting of Photovoltaic modules, batteries and a charge controller and producing up to about a thousand watt-hours per day. Photogensets are stand-alone AC systems incorporating a generator as backup for the PV in addition to a DC-AC inverter and battery charger.

The program tasks for the two-year contract consisted of designing and fabricating prototypes of both a MAPPS and a Photogenset to meet agency listing requirements using modular concepts that would support development of families of products, submitting the prototypes for listing, and performing functionality testing at Sandia and NREL. Both prototypes were candidates for UL (Underwriters Laboratories) listing. The MAPPS was also a candidate for FM (Factory Mutual) approval for hazardous (incendiary gases) locations.

During the first phase (one year from September 8, 1995 through September 7, 1996) SES researched the UL requirements and established contracts with both UL and FM, designed both the MAPPS and Photogenset, and began fabrication of the MAPPS. SES also developed the specifications and drawings for the designs, generated a Safety Requirements report summarizing UL and FM requirements and efforts, and developed a manufacturing plan for MAPPS product line development. Some specific accomplishments include development of 1) a lower cost battery/ control enclosure for the MAPPS, 2) an updated MAPPS Installation Manual and 3) a multi-platform Photogenset design.

During the remainder of the contract, SES completed fabrication of the MAPPS and Photogenset, obtained UL listing and FM approval of a family of MAPPS products, completed the UL investigation of the Photogenset opting not to obtain UL listing because of high cost and technology limitations, and obtained functionality testing of the prototypes at NREL and Sandia. SES also upgraded the MAPPS manufacturing process specifications and the Photogenset manual. Reports were generated on the certification process and on the functionality testing. 
There were several major accomplishments and technical milestones from the contract:

1) SES has developed a standardized family of MAPPS units encompassing a range from small $10 \mathrm{~W}$ modules with a single small battery to $300 \mathrm{~W}$ units with four $98 \mathrm{~A}-\mathrm{hr}$ batteries.

2) The standardized MAPPS systems are the first complete PV systems to be UL Listed and

FM Approved.

3) SES has also obtained UL listing of its combiner boxes and battery/control enclosures which can be sold as separate items.

4) The Photogenset employs a combination of components and capabilities not previously found in hybrid PV systems such as a remotely programmable system controller, an automatic oil change system for the generator, and a split-phase generator bypass breaker assembly all implemented in a trailer-mounted system.

5) In addition, the Photogenset also has the capability to be UL Listed though some additional technological maturity is needed to make it economically feasible.

6) SES has provided the PV industry and Underwriters Laboratory with significant experience in obtaining UL listing on complete PV systems and generated a report that should prove valuable for future efforts.

SES has benefited greatly from the performance of the PVMaT contract - from product improvements, from the standardization of SES products, from the listing of its MAPPS units and from new marketing opportunities and increased sales. The PVMaT contract has permitted SES to research and resolve many design issues and discover how to obtain UL listing and FM approval of products. The standardization of products has resulted in product lines of MAPPS and Photogensets that can be produced more economically and with shorter lead times. Engineering time has been reduced and both assembly and quality control have been improved. It has also reduced the number of different components needed in stock by eliminating many minor variations in products. The listing of the MAPPS units has increased marketing opportunities and increased MAPPS sales. We have begun marketing to the users of FM Approved products and we are incorporating MAPPS and Photogensets in our GSA (General Services Administration) government product catalog. 


\subsection{INTRODUCTION}

\subsection{Background and Goals}

This report summarizes the activities performed and the goals accomplished during a two and a half year project entitled "Design, Fabrication and Certification of Advanced Modular PV Power Systems" by the Solar Electric Specialties Company under the auspices of the PVMaT (Photovoltaic Manufacturing Technology) project of the National Photovoltaic Program. The SES contract was funded under Phase 4A1 of the PVMaT project, "Product Driven System and Component Technology," which has the goals to improve the cost-effectiveness and manufacturing efficiency of PV end-products, optimize manufacturing and packaging methods, and generally improve balance-of-systems performance, integration, and manufacturing. The period of performance of the contract was from September 8, 1995 to April 7, 1998.

The goal of the SES contract, "Design, Fabrication and Certification of Advanced Modular PV Power Systems," was to reduce the installed system life cycle costs through development of certified (Underwriters Laboratories or other agencies) and standardized prototype products for two of our product lines, MAPPS ${ }^{\mathrm{TM}}$ and Photogensets ${ }^{\mathrm{TM}}$. The MAPPS (Modular Autonomous PV Power Supply) systems are used for DC applications up to about a thousand watt-hours. The Photogensets are hybrid PV/generator systems for AC applications. The results of these product upgrades have served the bases for developing commercial product lines of standardized, certified, packaged systems.

\subsection{Organization of Report}

A brief summary of the work breakdown structure of the entire contract plus highlights of the status and accomplishments are included in the first two sections. A more detailed discussion is contained in the rest of the report. A number of deliverables were specified for the contract and these have been completed and provided to NREL. None of the deliverables have been included in this report, but the information and results have been summarized as appropriate. More details can be found in the deliverables.

\subsection{Task Descriptions}

The contract effort was divide into two phases with one year for Phase I (9/8/95 to 9/7/96) and one and a half years for Phase II and final reporting (9/8/96 to 4/7/98.) The scope of work encompassed seven tasks, four for Phase I and three for Phase II, as described below.

\section{Task 1 - Modular Autonomous Photovoltaic Power Supply (MAPPS) Design}

This task consisted of product research and the design of a UL-certifiable MAPPS with nominal $200 \mathrm{~W}$ PV power and 180 amp-hour battery capacity. Complete design documentation and a drawing package were provided. The task also included a users' survey of SES customers to determine user preferences in system features and components. 
Task 2 - Modular Autonomous Photovoltaic Power Supply (MAPPS) Fabrication This task consisted of the fabrication of the $200 \mathrm{~W}$ MAPPS, generation of as-built drawings and development of a manufacturing plan for future product line standardization.

Task 3 - Design of $1 \mathrm{~kW}$ Photogenset

This task consisted of product research and the design of a UL-certifiable Photogenset with nominal $1 \mathrm{~kW}$ PV power and $4 \mathrm{~kW}$ inverter. Complete design documentation and a drawing package were also provided.

\section{Task 4 - Safety Certification}

This task consisted of research into certification issues and determination of the requirements for certification (or "listing") of the systems by UL or other certifying laboratories. It included submission of both the MAPPS and Photogenset designs for verification by UL and the submission of the fabricated MAPPS to UL for certification and UL listing. The task also included development of a safety requirements report on the results of the research.

\section{Task 5 - Fabrication of $1 \mathrm{~kW}$ Photogenset}

This Phase II task consisted of the fabrication of the $1 \mathrm{~kW}$ Photogenset, generation of as-built drawings and documentation of the manufacturing process. It also included assessment of the fabrication process for ease of manufacturing and production scale-up.

\section{Task 6 - Safety Certification}

This task was a continuation of the Task 4 activities into Phase II. It consisted of completion of the UL listing of the MAPPS and of the review of the Photogenset design by UL. If results of the Photogenset design assessment and listing costs should prove acceptable, then submittal of the fabricated Photogenset to UL would also be performed. The task also included a final report on the safety certification results.

Task 7 - Functionality Testing

This task consisted of functionality testing of the $200 \mathrm{~W}$ MAPPS and the $1 \mathrm{~kW}$ Photogenset at NREL and Sandia, respectively. It included development of the test criteria and protocol, the testing, and the generation of test reports. 


\title{
2.0 SUMMARY OF ACTIVITIES AND ACCOMPLISHMENTS
}

\author{
2.1 Task 1, Modular Autonomous Photovoltaic Power Supply (MAPPS) Design \\ This task was completed by the end of the third quarter of Phase I.
}

\section{User Survey}

The User Survey was completed early in the contract. Since the survey was not a deliverable and the results were published only in one of the monthly reports, we have included the results below. There were only 10 responses to the survey out of 37 sent out. It is not possible to make any sweeping conclusions based on the low sample size; however, some trends could be noted.

1. All respondents claimed confidence in their PV systems, would recommend PV to others and were satisfied with the power available.

2. The majority either maintain the systems themselves or have the installers maintain them. (Some responded Yes to both themselves and installer.) Only one has the system maintained by other than self or the installer.

3. Nine respondents admitted they did not conduct a cost analysis to decide whether to install a PV system or connect to the grid. The other respondent did not respond on this item.

4. In keeping with the above, seven respondents felt there was not adequate information available to compare costs.

5. The majority also claimed they would like to have more metering.

\section{Design of MAPPS}

The design of $200 \mathrm{~W}$ PV MAPPS system was completed on schedule. As part of this effort we developed a new, reduced volume, lower cost, battery enclosure. We researched the development of a new charge controller with several manufacturers who all expressed concerns about developing a controller to our specifications without any guarantee of a large sales volume. Therefore, we opted to employ an existing UL Listed controller. We continued to pursue this issue and had many discussions with controller manufacturers concerning developing new controllers that satisfy all our needs and are UL Listed. However, no small, MAPPS-sized, UL Listed controllers were developed as a result of these discussions.

Taking the listing requirements into consideration, we chose to employ only UL Listed and Recognized components and use conduit for array connections. We had many discussions with battery manufacturers and made them aware of the PV industry's need for more parameter data including cycle life information. We also documented the MAPPS performance requirements and design parameters and developed a complete set of drawings for the $200 \mathrm{~W}$ MAPPS which were submitted as a contract deliverable. The block diagram of the MAPPS and a photo of the unit installed at NREL are included herein. 


\subsection{Task 2, Modular Autonomous Photovoltaic Power Supply (MAPPS) Fabrication}

This task was started mid-way through the third quarter and was completed in the sixth quarter.

\section{Fabrication of MAPPS}

The fabrication of the $200 \mathrm{~W}$ MAPPS was completed in two phases. Since we designed a new Battery/Control Enclosure for our new MAPPS product line, it had to be tested along with the control assembly by UL for rain resistance before we could be secure in its use. Therefore, the fabrication of the full MAPPS and its submission to NREL was delayed until the enclosure and control system testing was completed. The MAPPS fabrication was then completed as soon as possible after UL testing. The drawing package was also updated with as-built changes.

\section{Process Specifications}

We updated our manufacturing process specifications to satisfy the requirements of the listing evaluation and the follow-up inspections. This was completed shortly after the MAPPS was sent to NREL and prior to the UL listing inspection.

\section{Installation Manual}

We also updated our installation manual to satisfy listing evaluation requirements and to make the manuals amenable to cover a family of products. The manual was finalized and sent with the fabricated MAPPS.

\section{Modularity and Standardization}

Upon completion of the MAPPS fabrication, we developed a manufacturing plan for future MAPPS product line standardization to further guide the development of a UL Listed family of MAPPS. We divided the MAPPS into subassemblies and identified candidate components for each of the subassemblies for different sizes of MAPPS. The final development of the UL MAPPS family was accomplished as part of Task 6, "Phase II Safety Certification."

\subsection{Task 3, Design of $1 \mathrm{~kW}$ Photogenset}

The design of the $1 \mathrm{~kW}$ Photogenset was completed by the end of the fourth quarter and the design documented as a contract deliverable. This documentation included a description and drawing package suitable for use in fabrication by SES. The Photogenset is a multi-platform design that includes both a trailer and a skid mounted enclosure. Although the Photogenset could be fabricated as then designed, a number of listing issues had been identified as discussed in Task 4 below. Therefore, the design was later refined upon resolution of these issues. The block diagram of the Photogenset is included herein. 


\subsection{Task 4, Safety Certification}

This task was started in the third quarter of the contract and was completed upon submission of the fabricated MAPPS to UL. During this task we obtained the technical and administrative requirements for UL listing (and for other certifications as noted below) including the follow-up inspection requirements. We also obtained listing fees and follow-up inspection fees as well as labeling requirements and fees. The designs of the $200 \mathrm{~W}$ MAPPS and the $1 \mathrm{~kW}$ Photogenset were submitted to UL for evaluation. The MAPPS design was also send to Factory Mutual (FM) for evaluation for hazardous (incendiary) locations. As a result of these evaluations, we established contracts with both UL and FM for certification of the MAPPS. Based on their reviews and the use of UL Listed and FM approved components, the only concern was the need for a one-time rain spray test performed by UL on the battery enclosure to verify this custom NEMA-3R design. The use of conduit for module interconnections was required for FM approval. The rain spray testing and completion of the certifications were accomplished during Phase II and are discussed under Task 6 below.

The UL evaluation of the Photogenset design uncovered a number of issues because of the complexity of the system and the lack of UL Listed stationary generators and inverter/chargers. Therefore, the design would need to be significantly modified or special UL listing would have to be done on non-UL Listed components. As a result we investigated several alternatives: 1) obtaining certification through another laboratory such as ETL Testing Laboratory, 2) using a UL Listed inverter with separate charger and a UL Listed RV generator, and 3) obtaining UL listing on non-listed generators and inverters. It became clear that whatever the final solution the cost of obtaining certification of the Photogenset would be at least twice that of the MAPPS certification. The research continued well into Phase II of the contract and is discussed under Task 6 below.

At the end of Phase I, SES developed a "Safety Requirements Report" detailing the certification requirements of each agency and the technical issues of each system.

\subsection{Task 5, Fabrication of $1 \mathrm{~kW}$ Photogenset}

The Photogenset fabricated by SES for this contract consisted of a mobile PV/hybrid power system contained within a highway-licensed, enclosed trailer. The actual fabrication was delayed well beyond the planned completion date because of the issues associated with developing a complete UL listable system. Following completion of the UL investigation discussed under Task 6 below, we completed purchasing components that could not be previously specified, fabricated the subsystems, assembled the complete system and performed shakedown testing (with subsequent correction of deficiencies and certain component breakdowns). The unit was shipped to Sandia Laboratories for independent functionality testing in February 1998. 


\subsection{Task 6, Safety Certification}

Task 6, Safety Certification, was the Phase II continuation to Task 4, Safety Certification. While Task 4 centered around determining requirements and submitting designs for review and comment, during Task 6, the activities were centered around obtaining the certifications of the MAPPS and Photogenset. These activities resulted in 1) the UL listing of a complete family of MAPPS units from $10 \mathrm{~W}$ to $300 \mathrm{~W}$ and in 12 and $24 \mathrm{~V}$ versions, 2) the FM approval for hazardous locations of a modified family of MAPPS in the same power and voltage range, and 3 ) the completion of a detailed investigation and recommendations by UL on the Photogenset. The FM Approved of the MAPPS required certain modifications from the UL Listed MAPPS in order to obtain non-incendiary rating by FM. Therefore, we have one family that is only UL Listed and another upgraded one that is UL Listed and FM Approved. The FM approval is for Class I, Division 2, Groups A, B, C and D as defined in section 3.6 below.

Based on the report from UL, SES has decided not to obtain UL listing of the Photogenset at this time. There issues associated with the generator, as noted above, and with the state-of-theart system controller as well as the need for a non-listed Three Wire Start Control combined to make the cost of the listing prohibitive at this time and under these conditions. We believe that UL listing may be feasible in the near future when more generators are listed and the other technologies have matured. Detailed results are contained in a "Safety Results Report for the 1 $\mathrm{kW}$ Photogenset" submitted under this contract.

\subsection{Task 7, Functionality Testing}

This task consisted of independent testing of the fabricated MAPPS and Photogenset units by NREL and Sandia. The $200 \mathrm{~W}$ MAPPS was sent to NREL where it was installed on a pole at the NREL PV Outdoor Test Facility, placed under load and instrumented for long term data collection. A test report was generated by NREL and SES after the first month of testing. This report was one of the contract deliverables. NREL continued collecting data for several months thereafter and will provide a test report on this recently completed testing. The testing was completely successful as the MAPPS supplied the load without any failures of the system. A few recommendations for minor installation improvements can be easily implemented in future systems.

The mobile Photogenset was sent to Sandia for operational evaluation testing. Sandia performed testing on the inverter and the PV array separately as well as on the complete Photogenset system. A test report was generated by Sandia and SES as one of the contract deliverables. The test objectives were compromised by a failure of the inverter cooling fan circuit which then caused the inverter to shutdown at high power levels and in its battery charging mode; however, the Photogenset showed the capability to supply the load as expected providing one week of autonomy without generator backup. The cooling fan circuit was modified by the manufacturer and the inverter was replaced after the Photogenset was returned to SES. 


\subsection{Overall Accomplishments and Benefits of the Project}

SES has benefited greatly from the PVMaT contract. These benefits have come in the form of 1) opportunities for resolving design issues, 2) the standardization of SES products, 3) the listing certification of its MAPPS units and 4) new marketing opportunities and increased sales.

The PVMaT contract itself has permitted SES to address many design issues such as 1) the use of gelled batteries on their sides, 2) redesign of our MAPPS battery enclosure for increased safety and reduced cost, 3) programmable, interactive battery charge controllers, 4) enclosures for mobile photogensets, 5) automatic oil change systems for generators, 6) collapsible array mounts for the photogenset enclosure, and 7) internal stowage of photogenset arrays. The contract also permitted us to discover how to obtain UL listing and FM approval of products.

The standardization of products has resulted in product lines of MAPPS and Photogensets that can be produced more economically and with shorter lead times while increasing quality and reliability. Engineering time is greatly reduced when standardized products are sold. Engineering is only required when modifications must be made due to special requirements or when component problems such as lack of availability or specification changes occur. Product assembly and quality control have also been improved and streamlined with the development of standardized assembly processes and QC testing procedures.

Standardization has also reduced the number of different components needed in stock by eliminating many minor variations in products. For our UL Listed MAPPS we have standardized on three sizes of controllers, two sizes of circuit breakers and three sizes of battery enclosure. We can purchase these components in larger quantities and reduce per-piece costs.

It is difficult to quantify the cost improvements because some have been offset by other modifications. For example, the cost of the four-battery enclosure has decreased by $15 \%$; however, we have switched from fuses on the controller back panel to circuit breakers on a dead front door for increased reliability and safety. The savings in the enclosure is offset by the increased cost of the circuit breakers and dead front. In addition, the UL listing and FM approval have continuing file maintenance and inspection fees. Overall, however, we are able to offer the UL Listed MAPPS at about the same price as the previous non-standardized, un-listed products. 
The PVMaT contract has permitted SES to obtain UL listing not only on the standardized line of MAPPS units but also on subsystems of the MAPPS. These include array wiring combiner boxes, battery/control enclosures both with and without batteries, and privately-labeled surge arrestors. A family of MAPPS units has also been approved for hazardous (incendiary) locations. These can be used in oil and gas fields and on associated pipelines. Although we have not obtained UL listing on the Photogensets because of technical and cost issues described below, the listing investigation has resulted in improvements in reliability and safety and provided us with a detailed knowledge of the listing issues. Listing may be feasible and cost-effective in the near future.

The listing of the MAPPS units has resulted in increased MAPPS sales. We have begun marketing MAPPS products to the users of FM Approved products and we are incorporating MAPPS and Photogensets in our GSA (General Services Administration) government product catalog. 


\subsection{TASK EFFORTS AND ACTIVITIES}

\subsection{Administrative Activities}

On October 17, 1995 SES hosted a Kick Off meeting for our NREL Technical Monitoring team at SES's main office in Willits, CA. Discussions covered the following topics: 1) Objectives of the project, 2) Scope of the work and tasks planned, 3) Schedules, milestones and deliverables, 4) Demonstration of SES's current working hardware, 5) SES's manufacturing capabilities and plans, and 6) Current status of the project.

In October 1995, the second month of the project, we created a Gantt chart to better monitor our progress of Milestones and Deliverables. This chart was updated weekly and helped maintain emphasis on the Milestones and Deliverables. Monthly Technical Status Reports were generated to keep the Technical Monitoring Team appraised of progress, problems and resolutions.

An Annual Program Review Meeting was held August 22, 1996 at the NREL offices in Golden, CO. It consisted of an open meeting providing an overview for NREL employees and a closed meeting for the contract Technical Monitoring Team. The closed meeting included a review of status and accomplishments, key issues, and Phase II plans. A First Annual Report was submitted to NREL in October 1996 and published in final form in February 1997.

The Phase II and Final Program Review Meeting was held at Sandia Labs on April 15, 1998. It consisted of an open meeting providing an overview for Sandia and NREL employees, followed by a demonstration of the mobile Photogenset and finally a closed meeting for the Technical Monitoring Team to wrap up all contractual requirements.

The SES staff engaged in the performance of this contract consisted of:

Glen Minyard, SES Production Mgr. $\quad$ Project Manager and Principal Investigator

Tim Lambarski, Production Engr. $\quad$ Asst. Project Mgr. and Lead Engineer

Barbara Payne, Production Admin. Administrative Assistant

Mike Ashmore, Sales Engineer Technical Consultation

James Padula, President Technical Consultation

Scott Williams, Sales Engineer Technical Consultation

The SES staff was augmented by the following contractors:

John Hannestad, Professional EE

Electrical Engineering

Ben Worcester, CAD Draftsman

Drawing Support

Jim Bird, Industrial Engineer Production Controls and Quality Assurance

John Wiles, SWTDI, Electrical Engr. Codes, Certification and PV Design

Chris Eberspacher, Unisun $\quad$ PV Applications and Markets

Mr. Wiles is a PV design expert at the Southwest Technology Development Institute at New Mexico State University. Mr. Eberspacher is a PV utilization expert at Unisun. 


\subsection{TASK 1, Modular Autonomous Photovoltaic Power Supply (MAPPS) Design}

The MAPPS design task was divided into two subtasks: User Survey and 200 W MAPPS design. The major deliverables were a report on the User Survey and the MAPPS design documentation including specifications and drawings.

\subsubsection{User Survey}

A User Survey was developed at the beginning of the contract to be sent to SES customers that are currently using systems of the type being addressed in this contract. The purpose of the survey was to obtain user preferences on MAPPS features to guide the design effort. The survey was mailed on December 6, 1995 to 37 SES customers. Initial response was very small, perhaps because it was mailed during the Christmas season. Therefore, we took the opportunity to make several changes and re-mailed it after the new year. In the end we received a total of 10 replies to our survey and that only because we solicited responses by phone from seven of the respondents.

Because of the relatively small number of responses from the survey, it is difficult and may be misleading to draw many inferences or conclusions. We summarized the responses in a spreadsheet and developed some general conclusions. The results have been included in the summary section 2.1 above.

\subsubsection{MAPPS Design}

As part of the MAPPS development effort, we designed a new enclosure for the batteries and controller. This design changed the aspect ratio, reduced the overall volume, added a segregated control compartment and reduced the cost of the enclosure from pre-contract costs. We developed and released an RFQ to a number of enclosure suppliers in order to obtain a vendor for the enclosure. After the winning response was selected (Name of the company is SES proprietary), we issued a contract for the vendor to develop the final fabrication drawings and provide two enclosures. The battery enclosure design developed by SES had to be expanded into a detailed set of drawings for fabrication. All fabrication requirements such as knockouts, hole position and dimensions, corner radius specifications, hinge details and rain abatement gutters had to be specified. By the end of Phase I, the fabrication drawings had been completed and accepted by SES and the fabrication was in progress. We received the prototypes early in Phase II and accepted them after performing incoming inspections.

RFQ's were also developed and released for a Charge Controller and a Lighting Controller. We were attempting to obtain designs for these components that would satisfy all our needs for a standardized line of MAPPS. However, we were not able to obtain any satisfactory responses to the RFQ's. The respondents either felt their existing units could satisfy enough of our requirements or they were not in a position to redesign their units without either a large fee or a guaranteed large order. We abandoned the attempt to develop the controllers through formal RFQ's and have been working with some of the manufacturers through continuing orders for their products and phone solicitation for changes. 
SES has manufactured many different MAPPS systems over the years. In this contract our goal was to develop a UL listable design that could form the basis for a standardized, low cost, reliable product line. We first developed a preliminary MAPPS design, sent it to both John Wiles at SWTDI and to Underwriters Lab, obtained a detailed report from John Wiles and verbal comments from UL, and finalized our design based on their comments. The final design uses UL Listed and Recognized components with a history of high reliability and a new, lowercost battery/control enclosure with more room for optional equipment such as lighting control, metering and remote data acquisition.

The MAPPS units all employ Siemens modules, side-of-pole mounts, SES array combiners, SES "Solar Cell" gel batteries, the SES battery/control enclosure and a control system with low voltage load discount and circuit breakers for switching and protection.

\subsection{TASK 2, Modular Autonomous Photovoltaic Power Supply (MAPPS) Fabrication} Task 2 activities were concerned with actual fabrication and delivery of a $200 \mathrm{~W}$ MAPPS unit along with as-built drawings plus 1) an upgraded Installation Manual, 2) the development of process specifications and instructions, and 3) a manufacturing plan for product line standardization encompassing a family of MAPPS.

\subsubsection{MAPPS Fabrication}

At the end of Phase I (September 7, 1996), the fabrication of the $200 \mathrm{~W}$ MAPPS was awaiting the delivery of the new battery enclosure. The final drawing package had not been completed in time for fabrication and delivery before the end of Phase I. However, two enclosures were delivered early in Phase II. Following incoming inspection one enclosure was sent to UL for their evaluation as discussed in section 3.5 below. The second enclosure was reserved for fabricating the MAPPS to be shipped to NREL. This fabrication was placed on hold until the first enclosure passed UL testing. Following successful completion of UL testing, the second MAPPS was fabricated and sent to NREL on January 31, 1997. An "as-built" drawing package was produced after the MAPPS fabrication. This consisted on fabrication drawings for the enclosure and the control assembly which were used in developing the process specifications.

\subsubsection{Process Specifications}

As part of this task we developed new production process specifications to standardize and streamline the in-plant assembly process. This will ensure that each order for a MAPPS will be filled using the same high quality standards and consistency of production which are required to satisfy UL follow-up inspection requirements. During the MAPPS fabrication, our industrial engineering consultant observed the procedures and assisted us in improving our assembly procedures and developing the process specifications. 


\subsubsection{Installation Manual}

Also part of this task was the drafting of a new Installation Manual for MAPPS which is constructed in modular form with a product line in mind so that the same format can be used for all manuals. To accommodate new products and options we need only replace the appropriate pages with no reformatting or page renumbering.

\subsubsection{Future Product Line Standardization}

We also developed a proprietary manufacturing plan to accommodate future product line standardization encompassing a family of MAPPS products. We broke down the MAPPS systems into subassemblies so that the product line could be developed along principles of modularity and standardization. Three basic subassemblies are employed: PV Array Subassembly, Control System Subassembly, and Battery Subassembly. A non-proprietary Manufacturing Plan document was generated after the fabrication was completed. This document was later used to guide the development of the final UL Listed product line.

\subsection{TASK 3, Design of $1 \mathrm{~kW}$ Photogenset}

The performance of Task 3 encompassed components surveys, performance modeling, component selection, and both preliminary and final prototype designs and drawings for the Photogenset.

SES started the development of the $1 \mathrm{~kW}$ Photogenset by reviewing existing Photogenset designs. The next step was to develop a computer model for the Photogenset components so that a trade-off study could be performed to determine the optimum battery capacity and PV to Generator ratio. Manufacturers were contacted to obtain the latest data on battery capacity and cycle life versus discharge rate, generator maintenance and repair costs, fuel consumption rates and costs of various equipment. We also developed load and weather data for several locations. The analyses were performed using both the Siemens Stand-Alone System sizing program and the System-Spec program. Based on our analyses we chose a battery capacity of approximately $1000 \mathrm{~A}-\mathrm{H}$ and a generator power rating of $6.5 \mathrm{~kW}$ for a $1 \mathrm{~kW}$ PV array.

A major effort has also been expended in determining the enclosure for the Photogenset. We began by contacting manufacturers of portable and wheeled containers. We settled on a multiplatform design employing a custom enclosure that can be mounted on a skid or on a flat bed trailer. For this contract we chose to build the mobile (trailer-mounted) enclosure because it provided the greatest challenge and would cover the skid mounted option by default.

In the electrical design of the Photogenset, we first developed a preliminary design which was sent to UL for comment and to solicit a quote for listing evaluation. We also engaged John Wiles, SWTDI, to address the issues involved in reliability of various battery types for Photogenset usage and for UL certification. John provided us with a report and UL provided us with verbal comments both of which were used to develop the final design 
Although the final design at that point was complete and suitable for fabrication, we expected some modifications would still be needed because of problems with UL listing as discussed below under Task 4. Following a detailed design investigation performed by UL, the design was modified and finalized to incorporate lessons learned from this investigation.

As part of this task we also began to review the requirements for remote data acquisition and transmission. We reviewed literature on available remote monitoring and telemetry systems both in the telecommunications market and in remote commercial applications. We also reviewed the products being offered by other PV systems suppliers. We decided to incorporate remote control and monitoring in the charge controller by using a microprocessor-based, programmable controller with a modem. The resultant PMC9700 controller is manufactured to our specification and private labeled for SES.

After an extensive review of available and near term inverters, we chose the Vanner TSC24400D $4 \mathrm{~kW}$ sinewave inverter which operates at $24 \mathrm{Vdc}$, is UL Listed and produces 120/240 $\mathrm{Vac}$ in one unit. This unit also includes a remote control panel with a digital display and keypad for programming and monitoring from a separate wired location.

We also designed a 120/240 Vac transfer switch employing circuit breakers to permit running the load directly from the generator while bypassing the inverter. The power processing and control equipment is incorporated into a single powerboard that contains the charge controller, inverter, bypass switch assembly and both DC and AC disconnect breakers.

After an extensive review of battery issues and availability, we chose to employ sealed-valve release batteries because there are numerous models that are UL Recognized compared with flooded batteries and because they can be used without fear of acid gas corrosion. The batteries employed are the Deka Unigy II 3AVR85-21 batteries rated for 875 A-hrs at the 8 hour discharge rate and $1056 \mathrm{~A}-\mathrm{hrs}$ at the 24 hour rate.

The final design of the Photogenset employs a $900 \mathrm{~W}$ array consisting of 10 Siemens SR90 modules mounted on the outside of the enclosure on a variable tilt structure that can be collapsed onto the side and roof of the trailer and also disassembled and stored inside the enclosure.

\subsection{TASK 4, Safety Certification}

Task 4 addressed the Phase I activities associated with obtaining UL (and other possible agency) certifications for the MAPPS and Photogenset. Phase II activities were organized into a separate task, Task 6. In Task 4, we researched the certification requirements, submitted designs of the MAPPS and Photogenset for UL review and submitted MAPPS hardware for UL testing. 


\subsubsection{Determination of Listing Requirements}

The results of our investigation into safety issues, code compliance and safety certification listing are discussed in detail in the Safety Requirements Report submitted as a contract deliverable.

We began this effort by contacting Tom Lundveit, Underwriters Laboratories, Northbrook IL, to discuss our plans and obtain information on submitting products for UL listing. We provided Mr. Lundveit with company literature and a preliminary design of the $200 \mathrm{~W}$ MAPPS to obtain a quote on the listing evaluation. Mr. Lundveit provided us with product submittal and documentation requirements.

In conjunction with this effort, we contacted other PV suppliers who have UL Listed components to obtain their experience with the UL listing process and its requirements. We also discussed the UL listing process with John Wiles and obtained some documentation from him on issues related to code compliance and UL listing of PV components. We also obtained copies of various UL Standards:

UL 1741 Power Conditioning Units for use in Residential Photovoltaic Power Systems

UL 1778 Uninterruptible Power Supply Equipment

UL $50 \quad$ Enclosures for Electrical Equipment

UL 1236 Battery Chargers

UL 508A Industrial Control Panels

\subsubsection{Listing of MAPPS}

Mr. Steve Jochums was assigned by UL as our evaluation engineer. Subsequently, he provided us with a quote for the evaluation along with an Application for Evaluation. We also received a Follow-Up Services Agreement outlining the follow-up inspection requirements. Based on this information we established a contract with UL for the listing evaluation of the MAPPS.

Communication with UL revealed that a new subcategory would be initiated for our products. We were concerned about the lack of a UL standard for complete PV systems; however, they informed us the issues were sufficiently well-understood that no standard was needed prior to evaluation and no additional cost would be incurred because of the lack of a formal standard.

Subsequently we initiated contact with Factory Mutual Research Corporation (FM) to obtain information on FM approval of products for hazardous locations. These relate to locations where combustible gasses, dusts and fibers are to be found as defined in NEC Article 500. They provided us with a quote, an application for investigation and the requirements for submittal of products and documentation. Based on this information we established a contract with FM for Class I, Division 2 approval evaluation of the MAPPS. This is the same class and division to which numerous PV modules are already certified. The remainder of the FM approval activities were conducted as Phase II efforts and will be discussed in section 3.7 below. 
Since we made maximum use of UL Listed and Recognized components in our design, the only concern voiced by UL was for the custom-designed battery/control enclosure. UL expressed a need to perform a rain-spray test on the enclosure to verify it as meeting NEMA 3R outdoor requirements. UL also scheduled other routine tests in accordance with UL1741. Once we received the enclosure, it was sent to UL for its evaluation. We also provided UL with a control assembly and our array combiner box. UL did not require modules, mounts or batteries because the application of these components were straightforward. The remainder of the UL listing activities were conducted as Phase II efforts and will be discussed in section 3.7 below.

\subsubsection{Listing of Photogenset}

With the intention of establishing a contract for UL listing of the $1 \mathrm{~kW}$ Photogenset, we sent the detailed design to UL for review and to obtain a quote. UL identified several issues relating to the complexity of the system and the lack of UL listing on stationary generators and inverter/chargers. There were no UL Listed stationary generators, but a standard, UL 2200, was being developed. However, no manufacturers were as yet signed up for listing of their stationary generators. There were CSA Listed stationary generators, but UL would have to perform an evaluation and might require some testing. There were UL Listed RV generators, but they might require some evaluation for our application.

At the start of this effort there were no UL Listed inverters with built in chargers. The Trace inverter/charger was ETL rather than UL Listed so that a considerable effort would be required to obtain listing with this inverter. We researched the availability, cost and features of other inverter options, but had not found any good alternatives by the end of Phase I.

Because of the problems and unknowns associated with obtaining a UL listing on the Photogenset, UL proposed performing an initial scoping evaluation to determine the extent and cost required for the listing evaluation. The results of this initial evaluation would apply directly to the listing effort and reduce the subsequent cost. However, at that time cost was yet unknown.

As a result of these problems, we began to pursue listing of the Photogenset with the ETL Testing Laboratory because the Trace inverter was ETL Listed and it might be easier to obtain overall listing. We subsequently obtained a quote from ETL and obtained the submittal and documentation requirements for safety listing of the Photogenset. ETL stated they would accept the CSA listing of the stationary generators; however, in spite of this the cost was much higher than the estimated cost of the UL initial evaluation and also higher than the budget for the Photogenset listing. At this point, we could not determine which listing would be more costeffective; however, we had time yet before the planned fabrication of the Photogenset to refine our information and make our decision. 
This was the status at the end of Phase I. Follow-on activities and resolution of all issues were accomplished in Phase II and are reported in section 3.7 below.

\subsection{TASK 5, Photogenset Fabrication}

The fabricated Photogenset consists of a $900 \mathrm{~W}$ array on a mobile, towable trailer housing a 4 $\mathrm{kW}$ sinewave inverter, $875 \mathrm{~A}$-hr battery bank, a remotely-accessible, programmable controller, a $6.3 \mathrm{~kW}$ propane-fueled engine generator, and associated equipment and switchgear. The $900 \mathrm{~W}$ array is configured in two subarray assemblies of 5-modules each that can be stored inside the enclosure for shipping and mounted on the side and roof of the trailer for operational deployment. The Photogenset also includes an outdoor main breaker box and outdoor main service receptacles. Propane is supplied by the user, but a point of connection with a pressure regulator is provided on the outside of the trailer. Pictures of the Photogenset are enclosed.

The fabrication of the Photogenset was delayed during Phase II because of the issues identified concerning UL listing of the Photogenset and uncertainty about the charge controller, inverter and generator listing requirements. Once the issues were resolved as discussed in section 3.7 below, we proceeded with ordering components and with fabrication. The flatbed trailer was purchased first. It was sent to our metal fabricator who designed and fabricated an enclosure onto the flatbed trailer. We fabricated the power processing subsystems in our production facility prior to mounting them in the trailer. These consisted of the array combiner, the charge controller assembly and enclosure, the inverter bypass breaker assembly, and the powerboard containing the controller, inverter, bypass switch and disconnects.

Following assembly of all components within the trailer enclosure, we checked out the operation of all equipment and systems. After minor modifications, we performed an operational test at a remote residence. This testing uncovered some deficiencies that were subsequently corrected prior to shipment of the Photogenset to Sandia in February 1998.

\subsection{TASK 6, Safety Certification}

This Phase II task encompassed completing the UL listing of the MAPPS, submitting the MAPPS for FM approval and completing the FM approval, and completing the UL investigation of the Photogenset.

\subsubsection{MAPPS Safety Certification}

The first of the Phase II activities was the testing of the MAPPS hardware by UL. The battery/control enclosure passed the rain spray test and all submitted hardware passed the remainder of the testing. At this point UL began to develop the investigation report. 
During the investigation we developed a family of MAPPS encompassing a range from single 10 $\mathrm{W}$ modules with a small battery up to four $75 \mathrm{~W}$ modules with four $98 \mathrm{~A}-\mathrm{hr}$ batteries. We coordinated the designs and requirements with UL so that when the investigation of the MAPPS was completed, UL included the full family of MAPPS in the approval report. We also obtained separate listing for our combiner boxes and for the battery/control enclosure assemblies to be sold as stand-alone products.

Following completion of the report, UL also generated an inspection procedure for the followon in-plant inspection program for our products. The initial in-plant inspection was performed in April 1997. Following this inspection we were authorized to label the MAPPS products as UL Listed.

Once the hardware was returned by UL, it was refurbished because UL had damaged the enclosure and the charge controller during testing. It was then modified to include a hermetically sealed load relay to meet hazardous location requirements and shipped to FM for their evaluation. FM operated the equipment and made temperature measurements within the enclosure to ensure the temperatures were below incendiary levels. The equipment passed FM testing and a preliminary report was developed by FM.

At this point we began to address the issue of obtaining approval on the family of MAPPS and the combiners and enclosures as was done by UL. FM agreed to include the full range of MAPPS sizes that were listed by UL; however, FM would not approve the subsystems for separate listing because they felt this was contrary to their requirements of ensuring complete system safety.

Following generation of the preliminary report FM conducted an in-plant inspection at SES in December 1997. Following the successful plant inspection, FM finalized the MAPPS report and authorized us to place the FM label on our MAPPS products.

\subsubsection{Photogenset Safety Investigation}

At the beginning of Phase II there were several UL listing issues that had not been resolved. As a result, we considered the possibility of ETL listing instead of UL listing on the Photogenset. There were two issues that helped us make our decision. First, we found that Vanner was placing on the market a new UL Listed sinewave inverter that had previously been proprietary to another company. Since it was a $4 \mathrm{~kW}$ inverter/charger it met our requirements and we decided to use this inverter. Second, the cost of the UL Preliminary Investigation was much lower than the ETL listing cost. We were not willing to expend the funds for the ETL listing when we were not sure the Photogenset could meet all listing requirements. Therefore, we decided to contract for the UL Preliminary Investigation. If it provided desirable results we could go on with the listing; if not, we could stop there and not commit to a large sum. 
The UL Preliminary Investigation identified the evaluations and testing that would be required and estimated the costs. The costs were still lower than the ETL costs, but were sufficiently high to discourage completing the listing. In addition, it was noted that the charge controller and the generator would require detailed investigations and testing. There was no guarantee they would pass testing without possible modifications. There was a possibility that the cost of the listing and design modifications could swell beyond expectations. Therefore, we opted not to complete the UL listing at this time. We believe that, when the controller technology matures and when generators start to be UL Listed, the listing of the Photogenset will become more feasible.

\subsection{TASK 7, Functionality Testing}

Functionality testing was performed by NREL on the 200 W MAPPS unit and by Sandia on the $900 \mathrm{~W}$ mobile Photogenset.

\subsubsection{MAPPS Functionality Testing}

The $200 \mathrm{~W}$ MAPPS system was delivered to NREL for functionality testing in the first quarter of 1997. NREL erected a pole for MAPPS at their Outdoor PV Test Facility, installed the MAPPS, instrumented it for testing with NREL's new data acquisition system and began accumulating data. Prior to testing the MAPPS was characterized to determine PV rating and battery capacity. The MAPPS was loaded at 30 A-hr/day continuous with a low-pressure sodium lamp. NREL discovered some misprints in the Installation Manual and suggested some minor improvement to the mechanical design. Otherwise, the installation and operation were completely satisfactory. During the first month of testing there were no failures or load disconnects indicating the PV array was successful in keeping the batteries charged even during a two-day period of inclement weather. A test report was generated by NREL from the first month of testing. SES incorporated this report with analysis and comments into a SES contract deliverable. NREL will provide another test report to SES when the testing is completed.

\subsubsection{Photogenset Functionality Testing}

The mobile Photogenset was delivered to Sandia for functionality testing in February 1998. Sandia initially disconnected the inverter and performed functional testing on it prior to testing the Photogenset. The PV array was also characterized to determine array power rating and efficiency and to characterize losses. The Photogenset was instrumented with a $4.8 \mathrm{~kW}$-hr/day continuous load and operated under actual outdoor conditions. The Photogenset satisfied load requirements with one week of autonomy as expected. Unfortunately, there was not sufficient time available to perform full system testing because of a failure in the cooling fan circuit of the inverter. The inverter continued to operate but could not be used at high power levels or for battery charging because it would shutdown due to an over-temperature condition. The inverter has since been repaired, but only after testing was completed. 
In the testing of the inverter prior to cooling circuit failure, the measured efficiency of the $4 \mathrm{~kW}$ inverter versus load matched the manufacturer's specifications within $1 \%$ except at high power where the efficiency at $4 \mathrm{~kW}$ was higher than specification (83\% instead of $78 \%$.)

The performance of the PV array was measured with a curve tracer over the course of one day and normalized to standard test conditions (STC) of $1 \mathrm{~kW} / \mathrm{m}^{2}, \mathrm{AM} 1.5,25^{\circ} \mathrm{C}$ to obtain an array rating. The testing indicated the nominal $900 \mathrm{~W}$ array is actually capable of producing 828 W. This $8 \%$ loss is typical for PV arrays in which mismatch losses for crystalline silicon will be about $5 \%$ and wiring losses through wires, connections and circuit breakers will be about 2-3 $\%$.

A test report was generated by Sandia and incorporated with SES analysis and comments into a SES contract deliverable. 


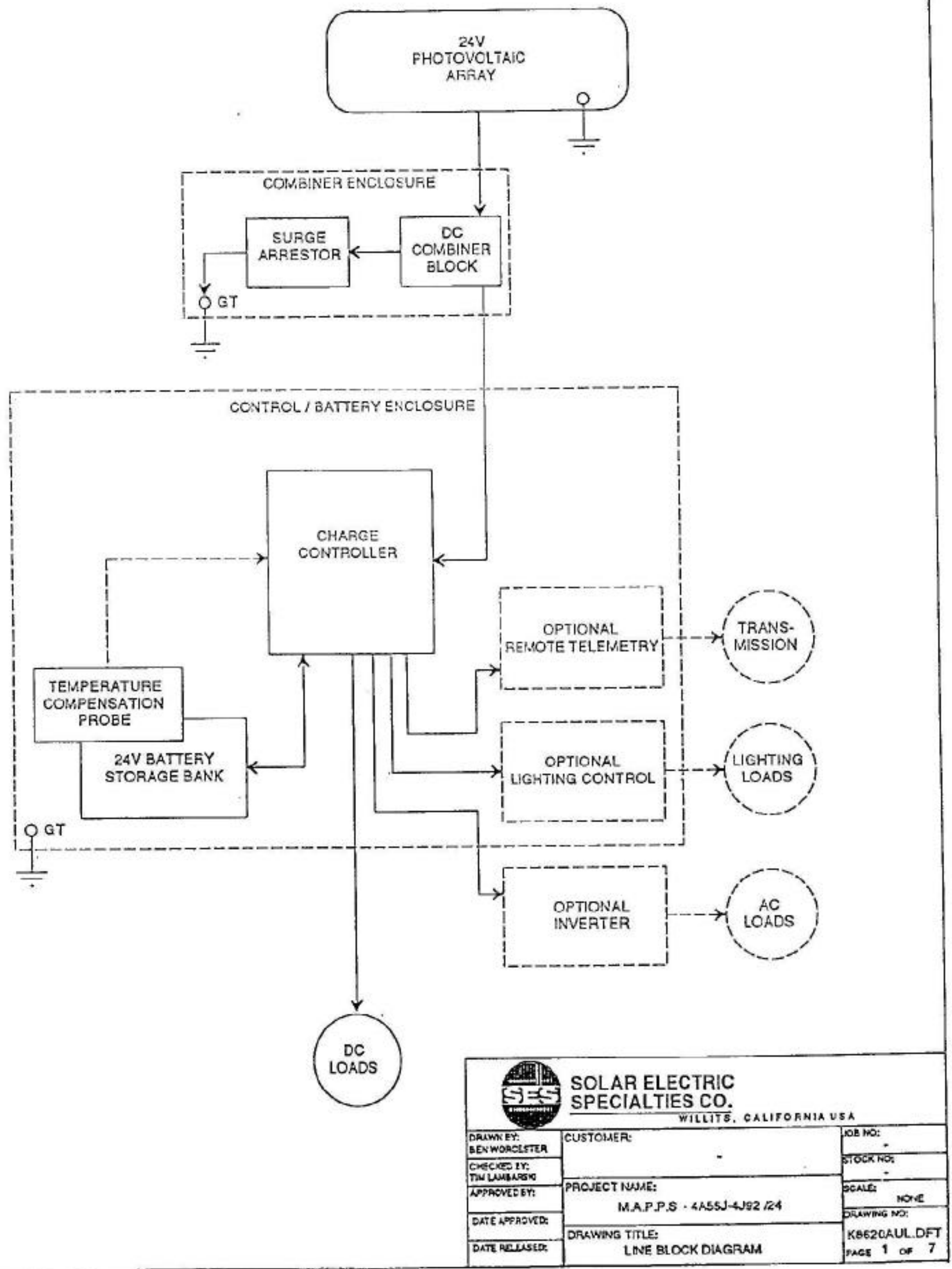




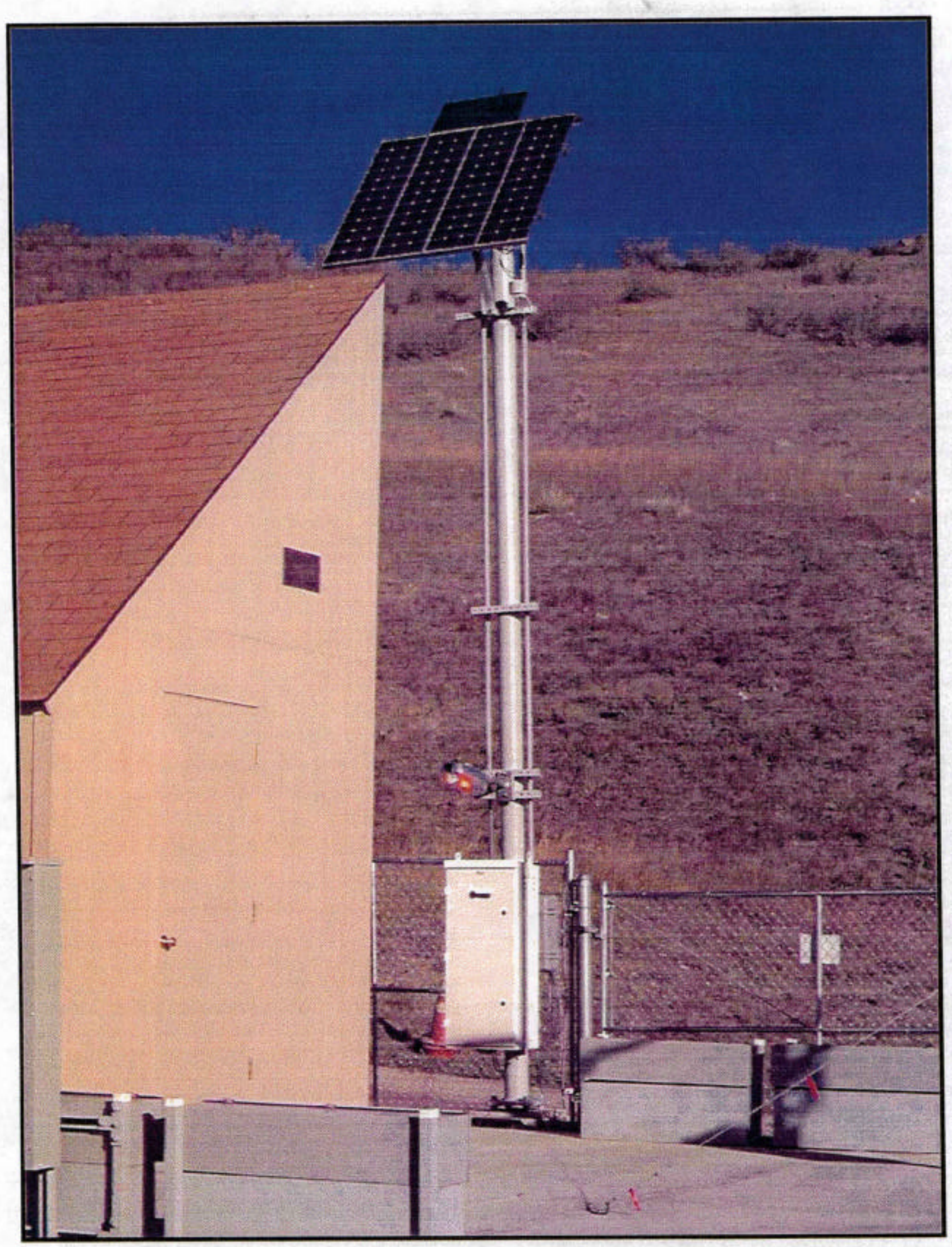

The SES 200 W MAPPS system under test at NREL OTF 


\section{MOBILE PHOTOGENSET BLOCK DIAGRAM}

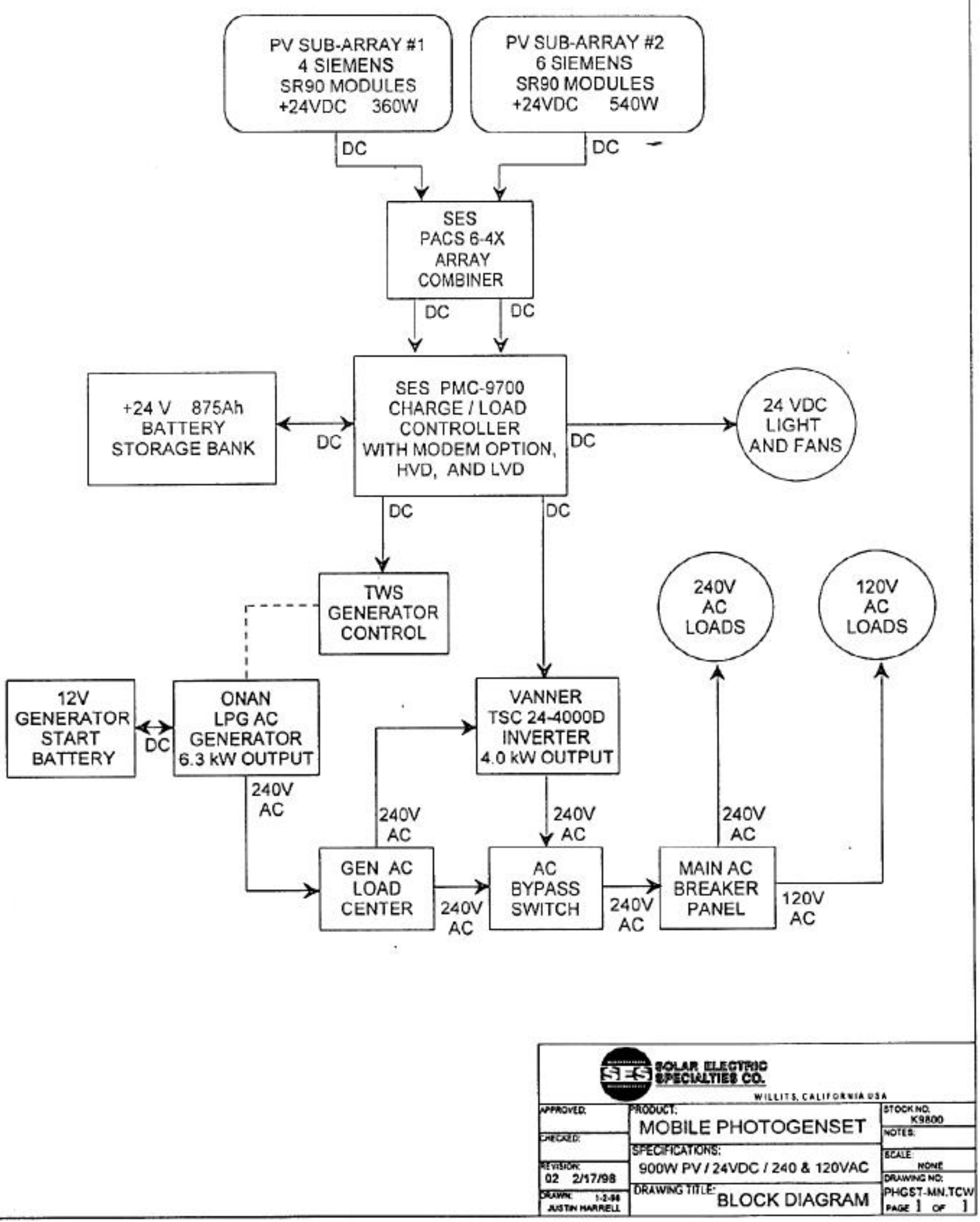




\section{MOBILE PHOTOGENSET \\ TRAILER PLAN VIEW}

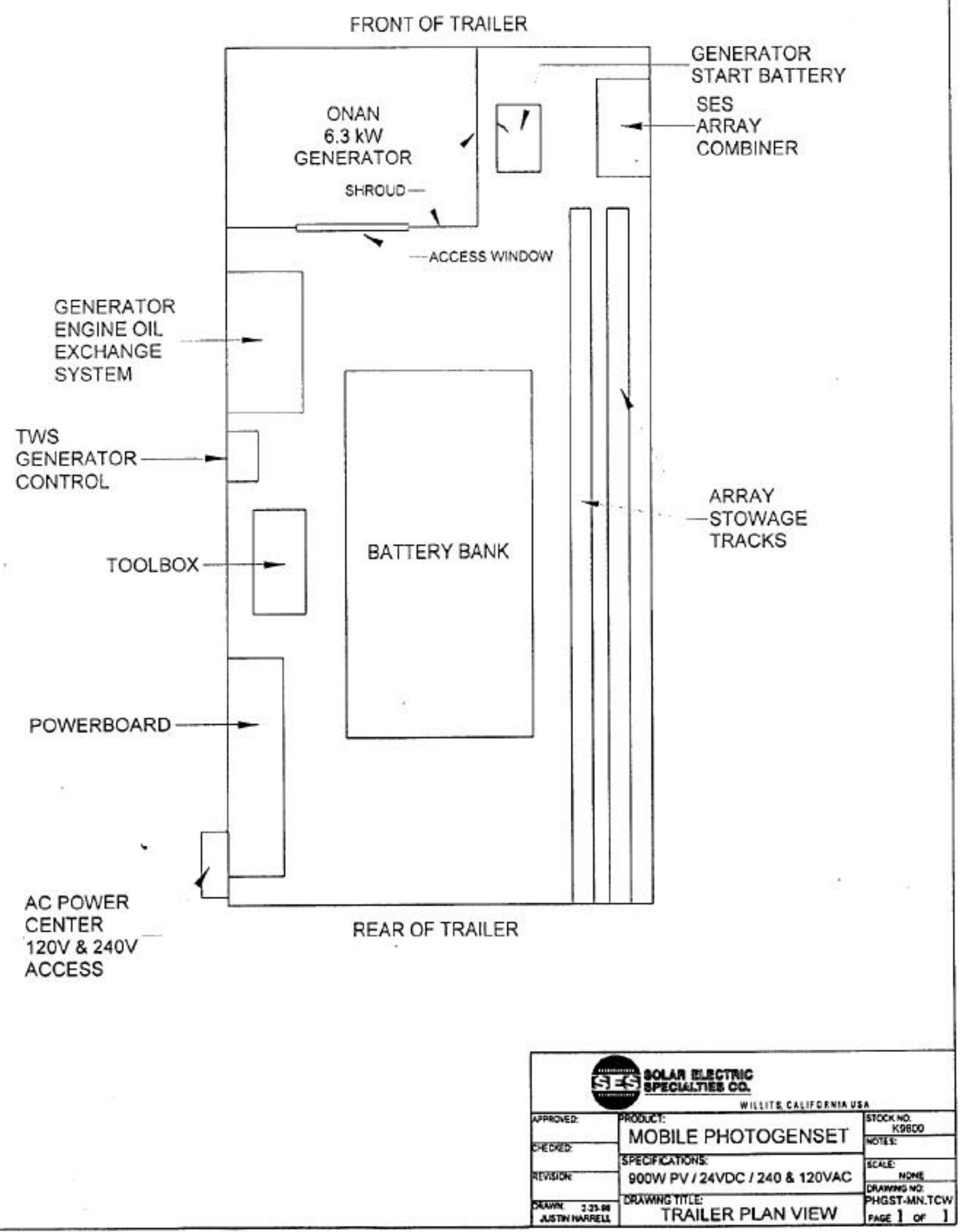




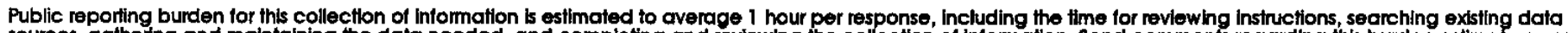

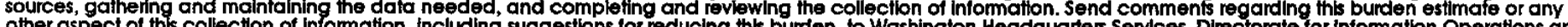

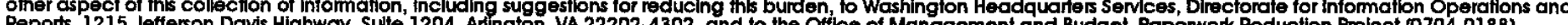
Rashington, DC 20503.
Wais Highway, Sulie 1204, Arington, VA 22202-4302, and to the

\begin{tabular}{|l|l|l|l}
\hline 1. AGENCY USE ONLY (Leave blank) & $\begin{array}{l}\text { 2. REPORI DATE } \\
\text { October } 1998\end{array}$ & $\begin{array}{l}\text { 3. REPORT TYPE AND DATES COVERED } \\
\text { Final Technical Progress Report }\end{array}$
\end{tabular}

\section{TITLE AND SUBTITLE}

Design, Fabrication, and Certification of Advanced Modular PV Power Systems; Final Technical Progress Report

6. AUTHOR(S)

T. Lambarski and G. Minyard

7. PERFORMING ORGANIZATION NAME(S) AND ADDRESS(ES)

Solar Electric Specialties Co.

P.O. Box 537

Willits, CA 95490

9. SPONSORING/MONITORING AGENCY NAME(S) AND ADDRESS(ES)

National Renewable Energy Laboratory

1617 Cole Blvd.

Golden, CO 80401-3393

\section{FUNDING NUMBERS}

C: ZAF-5-14271-07

TA: PV805101

8. PERFORMING ORGANIZATION REPORT NUMBER

\section{SUPPLEMENTARY NOTES}

NREL Technical Monitor: H. Thomas

12a. DISTRIBUTION/AVAILABILITY STATEMENT

National Technical Information Service

U.S. Department of Commerce

5285 Port Royal Road

Springfield, VA 22161 12b. DISTRIBUTION CODE

\section{ABSTRACT (Maxdmum 200 words)}

This report describes the overall accomplishments and benefits of Solar Electric Specialties Co.(SES) under this Photovoltaic Manufacturing Technology (PVMaT) subcontract. SES addressed design issues related to their modular autonomous PV power supply (MAPPS) and a mobile photogenset. MAPPS investigations included gel-cell batteries mounted horizontally; redesign of the SES power supply; modified battery enclosure for increased safety and reduced cost; programmable, interactive battery charge controllers; and UL and FM listings. The photogenset systems incorporate generators, battery storage, and PV panels for a mobile power supply. The unit includes automatic oil-change systems for the propane generators, collapsible array mounts for the PV enclosure, and internal stowage of the arrays. Standardizing the products resulted in product lines of MAPPS and Photogensets that can be produced more economically and with shorter lead times, while increasing product quality and reliability. Product assembly and quality control have also been improved and streamlined with the development of standardized assembly processes and QC testing procedures. SES offers the UL-listed MAPPS at about the same price as its previous non-standardized, unlisted products.

14. SUBJECT TERMS

photovoltaics ; Photovoltaic Manufacturing Technology ; PVMaT ; modular PV power systems ; MAPPS ; photogensets ; certification

15. NUMBER OF PAGES

34

16. PRICE CODE

17. SECURIYY CLASSIFICATION OF REPORT Unclassified
18. SECURITY CLASSIFICATION OF THIS PAGE Unclassified
19. SECURITY CLASSIFICATION OF ABSTRACT Unclassifled
20. LIMITATION OF ABSTRACT

UL 